\title{
New Forms of Volunteerism in Public Health. Professionalization Processes in Complementary and Alternative Medicine Field
}

\author{
María Mercedes Saizar \\ mercedessaizar@conicet.gov.ar \\ Mercedes Sarudiansky \\ msarudi@gmail.com \\ Mariana Bordes \\ marianabordes@conicet.gov.ar \\ Guido Korman \\ gkorman@gmail.com \\ Researcher - Argentinean Center for American Ethnology- National Council of Scientific and \\ Technological Research -Argentina (Centro Argentino de Etnología Americana-Consejo Nacional de \\ Investigaciones Científicas y Técnicas).

\begin{abstract}
Based on a phenomenological and qualitative approach the paper will focus on the emergence and definitions of roles of a new type of social volunteers in the public health system of Argentina. The relevance of this election is based on the differential traits this way of participation has as against other modes of insertion in the health sector that existed in different historical periods; that is to say, the differences between old and new volunteers. In this framework, we will emphasize our analysis in how these new ways of volunteerism shape a series of strategies of inclusion of complementary and alternative medicines in the public healthcare system, introducing -in an unofficial manner-discourses and practices for healthcare different to those proposed by official biomedicine.
\end{abstract}

Keywords: Complementary and Alternative Medicines - Public Health-Workshops- Volunteerism.

\section{INTRODUCTION}

As a phenomenon traditionally related to Christian charity practices and care in western societies, volunteerism became in the last decades an especially interesting object for social sciences. Within this field, research has analyzed different traits of this phenomenon, distinguishing issues relative to the relation between public institutions and volunteerism and the non-profit sector [1], underlining the relation of age, gender and retirement as factors linked to motivation for volunteering [2] [3] [4] and noticing the growth of the volunteers sector in the provision of diverse public and non-profit services [5] [6]. This last aspect has been connected to the increasing direct intervention of civil society in different areas of the State, more specifically in the Healthcare Area [7].

In this context, marked by complexity, the present paper will focus on the specificity of the new volunteers. The relevance of this election is based on the differential traits this way of participation has as against other modes of insertion in the health sector that existed in different historical periods; that is to say, the differences between old and new volunteers. In this framework, we will emphasize our analysis in how these new ways of volunteerism shape a series of strategies of inclusion of unconventional medicines in the public healthcare system, introducing -in an unofficial mannerdiscourses and practices for healthcare different to those proposed by official medicine. We refer to the case of Yoga, Reflexology, Biodances and Tai-Chi-Chuan experts, among other therapists, who enter hospitals as volunteers.

In the light of the aforesaid, this paper will be divided in two sections. In the first section we will address the potentialities for the participation of the civil society from the figure of volunteerism. To do that, we will focus on the way in which such activities are regulated in legislation in Argentina. In the second section, we will analyze the way in which new volunteers are inserted in the institutional network of some public hospitals in the city of Buenos Aires, where we undertook our field study, detecting struggles, tensions and negotiations with other actors in the health sector. The election of this city was based on the fact that it represents the largest conglomerate of inhabitants of Argentina, with around 13,000,000 inhabitants -combining the central area of the city and its suburban area-, being also the capital of the nation and the political and administrative see of the national territory. 


\section{METHOD}

The methodology used to develop this work is based on a phenomenological and qualitative approach and is aimed at understanding how new ways of volunteering emerge in the hospitals of the Autonomous City of Buenos Aires, especially focusing in the complementary and alternative medicine field. Currently the city of Buenos Aires has thirteen General Hospitals (or Acute hospitals) that depend of the city government. Generally speaking, these are complex units of comprehensive health care that offer free attention to the population of all ages located in their area of influence, through the offer of several specialties in biomedicine, dentistry and psychology. They are part of the national healthcare system, which ensures free public attention to all the inhabitants of the country.

This methodology uses inductive reasoning prioritizing field collected data to generate a hypothesis. This research is based on the idea that interpretative understanding is only possible by deconstructing the phenomenon's meanings [8] [9].

For this study we selected three out of the five Acute Hospitals offering alternative therapies workshops for the general public in the Autonomous City of Buenos Aires. In two of the selected hospitals, the workshops were organized by the Mental Health Area. In the third one, it was organized by an external non-profit organization. For this study we interviewed the general coordinators of the workshops. We also interviewed twelve volunteers -four in each hospital- among which we found alternative specialists in the following therapies: Circular Dances, Tibetan Singing Bowls, Yoga, Tai Chi Chuan, Transcendental Meditation, Bioenergetics and Reflexology.

Interviews to coordinators and volunteers were semi-structured on the base of a series of open questions about the use of these strategies in the hospital context. The following topics were considered for coordinators/ alternative specialists: a) organization of the workshops, b) reasons to create the workshops c) the reasons for referring to these workshops, d) ideas on health and disease and e) the role of volunteers, and the difference between other ways of volunteering.

The field work took place between April 2009 and September 2012, which included, also, participant observation of the activities delivered in these hospitals, and an extensive search of ways of volunteering in 12 other general hospitals in Buenos Aires, through primary and secondary sources. The interviews were recorded and transcribed literally. Duration varied from 30 to 90 minutes. Authorizations and informed consents were signed by every participant before interviews and participant observation. Informants' names were changed to preserve their identity.

\section{RESULTS AND DisCUSSION}

\subsection{The Figure of Volunteers in Legislation in Argentina}

In the first place, it is useful to underline that the figure of volunteers in national legislation became prominent only in the early 21 st century. It was in late 2003 when the National Law of Social Volunteering was passed -Law No. 25,855, regulating activities of those involved in 'solidarity activities'. It was only in 2010 that this law was regulated for its full entrance into force. In 2007, the City Council of Buenos Aires passed the law No. 2,579 for Social Volunteering in the jurisdiction, which has very similar traits to the national law, but its emphasis is put on the promotion of volunteerism rather than on its regulation. Both laws define the figure of social volunteer as “...physical persons who undertake, in their free will, in a free, altruistic and solidarity way, activities of general interest in organizations of the civil society, without receiving for that any remuneration, salary or economic compensation of any kind." (art. 3, National Law No. 25,855 and art. 1, sect. c, law No. 2,579 Autonomous City of Buenos Aires), underlining the importance of the regularity of volunteer activities, given that it excludes temporary activities from the definition, which are subject to family or community interests, or in the case there is a contractual obligation.

Regarding the delimitation of the areas of insertion of such activities - "organizations in which social volunteering is practiced", as the texts point out-, it is worth highlighting that these laws are not circumscribed to a specific sector and that the activities promoted belong to different areas of the social sphere. These organizations are defined as "...People of legal entity, public or private, nonprofit, whatever their legal status, participating directly or indirectly of programs and/or projects oriented to the pursue of common good and general interest, taking place in the country or abroad, 
having or not State support, subsidies or patronage" (art. 2, National Law No. 25,855; art. 2, sect. b, Law 2,579, Autonomous City of Buenos Aires). This implies that regulations proposed by national and city legislative bodies lacks specificity when identifying the areas in which volunteers take part, highlighting only the fact that these must be organizations whose goals are not limited to profit and promote 'common good', a concept vague enough to interpret a wide range of practices. Therefore, it is expectable that -since health is related to the general fulfillment of the population's needs, not only at the biological level but also at the social and psychological levels, in their broad range, one could interpret that regulations present in the quoted laws ought to include health promotion oriented activities as pertinent areas for such goals. However, no official regulation of national or local reach regulates volunteer activities for the health sector specifically.

This observation is important not only due to a precise character nor a purely theoretical matter, but more so due to the fact that the health sector is one of the areas where legal regulations of the activities of those practicing their professions overlap, generates ethic and legal limitations concerning what is or not allowed to do with those accessing the system. In fact, there are regulations in this sector that fall to hospital professionals and employees through laws of professional practice, such as the National Law No. 17,132 for the Professional Practice of Medicine, Dentistry and Auxiliary Activities of such Practices (among the auxiliary practices we count nurses, occupational therapists, speech therapists, orthopedists and different technicians and auxiliaries of the medical subspecializations); National Law No. 23,277 for the Professional Practice of Psychology (from 1985, although regulated for its entrance into force in 1995) and Law No. 23,377 for the Professional Practice of Social Workers (1985). This means that in the sphere of public healthcare, very especially regarding health centers of public or state character, the range of relevant activities for each discipline is limited and pre-established by the laws that regulate it, segregating volunteer activities to a marginal or interstitial position, where capacity of action is restricted. In this direction, the complex scheme of rights, obligations, limitations and regulations we find in this sector is even intensified when we enter this new legal figure -that of volunteers-, whose specific actions have not been preestablished and therefore -based on the ambiguity of what could be included under the labels 'common good' or 'general interest' - are enabled to a great diversity of activities.

As we will see in the next section, volunteer activities performed in fact in the health sector are no longer restricted merely to the assistance or accompanying of the professional practice of hospital workers, but the offer has expanded to the point where the figure of the volunteer -currently protected by the aforementioned laws- has began a movement towards the independence from strictly biomedical practices. In this context, it is expectable to find the appearance of possible conflicts resulting from this juxtaposition of agents, sectors and regulations; conflicts related to the basic inclusion of these new practices in the areas of biomedical practice -as the case of public hospitals- to the limits of the intervention of such practices on the users of the health system.

\subsection{The Insertion of New Volunteers at the Institutional Level}

In Argentina, General Hospitals are complex units for comprehensive healthcare offering free services to the population of all the ages, circumscribed to the area of their geographical location, through the offer of several biomedical, dentistry and psychological specializations. The work dynamics of general hospitals corresponds to what has been called the second level of care, and implies a series of professional practices in consultation, diagnose, treatment and follow-up of the patients within the framework of the biomedical logics of understanding of health and disease. These institutions provide programmed and emergency medical attention, diagnose and treatment services -both in external medical offices and hospitalization-, in multiple medical specializations, targeted at patients requiring of services of higher complexity than Level I -primary attention- and less specific than Level III specialized attention.

In this context, Open Workshops are designed as part of the strategies of opening of the institutions to the population. They are targeted at chronic patients and their families, with the main goal of providing support and information about different pathologies, creating an environment of support and tutoring parallel to the biomedical treatment of the disease at hand. The coordination of the workshops is entrusted to different professionals in the permanent staff of the institution. Such positions are taken by psychoanalysts, dieticians, grammatologists and social workers, who act in 
coordination with the corresponding biomedical specialists and under the general supervision of the hospital's direction. In some cases, the supervision is undertaken jointly by the direction of the hospital and the person in charge of a specific area of the institution, for instance the Programmatic, Research and Teaching, Gynecology or Mental Health Areas.

The design and coordination of such activities adjusts as a whole to the ways of understanding health and disease typical of the dominating paradigm, acting as a unifying axis and as a reinforcement of the treatment indications, behaviors and habits that specialists try to instill in their patients. In turn, it is expected that these groups enhance the settling of the biomedical knowledge and practices within the communities to which participants belong, amplifying their own discourse and achieving impact on broader social groups, evidencing a strategy that attempts to expand, beyond the doctor-patient encounter, the criteria to understand and define the conditions of health and disease [10].

\subsection{The Offer of Workshops Since New Volunteerism}

Within the three hospitals included in our field work, in the last years a change in the type of workshops offered has occurred, not only expanding the offer by increasing the amount of activities available, but also setting the emergence of an interesting phenomenon in the field of public health. We refer to a new type of movement that, even if it exists within the hospital sphere, it has certain traits that distinguish it from those described previously. Just as in the previous cases, these are free and open groups, but they aim at a broader coverage, since they are promoted for all hospital users, whether they are being treated or they are just neighbors of the institution, and even if they live in surrounding neighborhoods or other areas of the metropolitan region. In this new field of offers, workshops are defined by the diversity of the activities provided and by the novelty of their contents. We find then from literary workshops to film clubs with debates, theater, writing, loom workshops, painting and a series of activities that can be understood as art-therapy, as well as others increasingly highlighting the use of the body, such as Yoga, Tai-Chi-Chuan, circular dances, Shantala massages, Reflexology, Reiki, etc.. The goal is not focalized in the specificity of the attention-supportinformation around a given pathology, but rather on a wide spectrum of practices searching for an improvement in living conditions linked to individual and social well being, in a general sense. In other words, there is a clear guideline giving preeminence to the need to underlining the potential of each participant, associating the workshop's activities to work, communications, creation of social networks and improvement of life quality [11].

These uneven goals indicate, among other issues, the deep differences in terms of the frameworks for the understanding of the health-disease process in biomedicine and complementary and alternative medicine. One of the most broadly used definitions, found in numerous studies is the definition of the WHO [12] that proposes to call them complementary/alternative medicine [CAM] as for its use regarding biomedicine. As Naja et al [13] pointed out the United States National Center for CAM therapies divides complementary and alternative medicine into four categories: mind-body system; manipulative and body-based practices; energy medicine and biologically based practices.

In this direction, the notions of health and disease implied by alternative therapies integrate not only the micro and macro social aspects of the lives of individuals, but also an concept of human beings in which energy -in the sense of sacred power- plays a crucial role both in the etiology of the disease via unbalances in the amount of energy-as in the re-establishment of health -via harmonization of the amount of energy. As Clavarino and Yates [14] pointed out, alternative therapists usually state that diseases are caused by an unbalance between opposing energetic forces and adhere to a holistic orientation as part of their healthcare paradigm.

"These spaces allow thinking about the hospital from a different perspective, it's not associated to being sick any more but to trying to feel better, to reach a better quality of life ...it changed the image of the hospital as a place associated to death; there is a government policy promoting these actions, however, and before politicians thought about it, we were doing it spontaneously" (Julieta, coordinator).

Regarding the coordination tasks implied by these workshops, they widely differ from the old ones since they deliberately reject psychotherapeutic practices related to individual therapy and 
psychological interpretations usually used in group contexts, typical of the traditional psychoeducational workshops.

"Julieta always says that the hospital needs to change, to take care of the community members' wellbeing and not just treating diseases ... On our Saturday meetings for instructors she stresses that we should not go for psychotherapy and that we should promote healthy behavior using simple and clear language and avoiding technical jargon". (Roberto, Transcendental Meditation Instructor).

"Maria has a very open overview on health. When she called us she explained she was interested in offering a different space where patients could work on their health from a holistic point of view, based on the idea that health is a lot more than not being sick" (Betina, Circular Dance Instructor).

According to the opinion of the coordinators of these workshops, this new perspective would favor a connection between hospitals and health, thus generating a movement from the central role that death and disease have historically had in these institutional contexts.

"Disease is no longer the center, since the WHO focused on health as a state that covers the physical, emotional, and social aspects, so we must think about how to preserve and maintain healthy conditions instead of how to treat sickness" (Julieta, coordinator).

"We believe, and this is hard to accept especially for us, that a hospital is a place for sickness and death; Foucault says it in The Birth of the Clinic: hospitals are places where people go to die. So, a hospital is a place associated with sickness and death. Workshops work on prevention, which is different. It's a pity that a lot of my colleagues don't understand this" (Maria, coordinator).

What's remarkable about this new modality is the increasing presence in official spheres of health of practices usually linked to the New Age (biodance, circular dances, transcendental meditation) and even some of them -of clear oriental roots- such as Yoga, Tai-Chi-Chuan, and Tibetan singing bowls, Shiatsu and Reflexology, among others.

This 'alternative' workshops offer nonconventional therapies, some of them considered -according to WHO parameters [12] - within the group of the so-called 'complementary' therapies and others definitely belonging to the sphere of the alternative. The peculiarity of these workshops is that, besides proposing unconventional practices, they are coordinated by specialists of disciplines foreign to -and even contradicting with- biomedicine. In other words, the figure of the coordinators of alternative workshops differs from that of the coordinators of traditional workshops, as in this case they are people not only external to the institution but also foreigners to the guiding paradigm of hospital practices, which manage to enter the institution through the active participation in a collective of volunteers operating under the coordination of a biomedical specialist who is the responsible agent within the institution.

With regards to our object of interest, it is necessary to point out the way in which the so-called 'new' volunteers are included in the hospital system. Even if in all the institutions surveyed we were informed of the same method to recruit and select coordinators, the intermediate steps of the process vary.

"Every year, at the beginning of the year, we organize the activities' offer. We open a call for persons who are interested in teaching workshops. We ask them to bring their resumes and then we interview them. It's very important for us that they have credentials guaranteeing their training in the practice they are about to teach; that they have studied and obtained credentials. We want serious people that can perform responsibly" (Julieta, coordinator).

"Some reflexologists come and want to be coordinators since the first day. But we have to interview them and know which way they work, where they studied and what they expect this task. It is a task of great responsibility, is the health of people..." (Norma, coordinator)

In some cases, the search and selection of volunteers is carried out by the general coordinator, following a criterion that prioritizes the applicant's proposal beyond the formality of their degrees, taking into account their availability and the possibility of undertaking a task that requires of 
commitment and assuming responsibility without any pay. In other cases, it is a sine qua non requirement that the applicant can provide with proof of a systematic learning of the discipline that will be taught in the workshop, showing a clear trend towards professionalizing not only volunteer practices, but also mainly unconventional ones facing the dominant biomedical paradigm. In this direction, we have noticed the different ways in which traditional volunteers were included in the activities of the institution, since this always takes place within the context of charitable institutions mediating the connection volunteer-institution. The selection process of alternative volunteers shows the same traits as that of traditional ones, since the applicant's background and his proposal must be approved by the general direction of the hospital. Once the volunteers have been accepted, their tasks begin, which will be directly supervised by the general coordinators of the workshops.

In all the hospitals where unconventional workshops exist, these are largely coordinated by volunteers. They are the ones who without the economic support -and many times from the very margins of the institution- sustain and make these activities possible, while moving in an unstable environment, marked by a double marginality: on one side, the one of being volunteers -and therefore not being a part of the permanent staff of the institution - and, on the other side, that of coordinating unconventional activities that, due to a lack of legislation, are on the very edge of the institutional structure and the currently dominant biomedical paradigm.

\subsection{Struggles Between New and Old Volunteers: Between Charitable Activities and Professional Services}

In this new arena there is a distinction of responsibilities and actions regarding the design, general coordination and specific coordination of each activity. In that direction, while the design and specific coordination of the groups are associated to the sphere of a specific area - Programmatic or Mental Health Areas-, the specific coordination of each activity is developed by external personnel, who undertake these activities as volunteers and without being paid for them. The activity of these volunteers differs from that of traditional ones -usually linked to different charities- who had and still have a role mainly related to the assistance and support of biomedical professionals, to whom they report and who establish the type of tasks they will undertake.

The profile of the traditional volunteers in the hospitals of the Autonomous City of Buenos Aires is by majority female, above 50 and without a permanent job, not registered in the labor market and with an education level varying between incomplete high school education and incomplete university education, part of a charity that establishes the ways of collaboration, coordinates their schedules, distributes the tasks, etc. Their insertion in the daily life of the hospital is targeted, on the one hand, at providing emotional support and company to inpatients who are not accompanied by their families, but also -and probably mainly- at covering the lacks of permanent assistants to biomedical professionals, performing tasks such as assisting the ill in their personal hygiene, supporting women who have recently had a child in the care of the newborn (e.g., changing diapers, bathing them, making them sleep), handing out clothes for children of poor families, distributing medications to outpatients, organizing the spontaneous demand of internal offices, among other tasks. In this direction, such practices seem to preserve the aspects related to pre-professional stages of the areas of nursery and social work, given the predominance of support activities by other professions, undertaking care related tasks but banned from any type of decision-making. So, the figure of volunteers can be summarized as that of an assistant who performs his tasks closely following the criteria and decisions of another professional. The fact that they are not paid is sensed as a trait essentially defining their role as volunteers. With regards to the models of healthcare, these volunteers perform their tasks within the context of the current dominant paradigm of biomedicine, what places them in a subordinate position in terms of decision-making -since biomedical professionals are the ones who make the decisions.

The emergence of alternative workshops shows -among other, diverse aspects- the apparition of a new profile of volunteers. This is a diverse group, formed by both women and men between the ages of 20 and 60 with complete high school education, sometimes also with college education, but mainly with formal and systematic studies in the disciplines they teach, with a steady job -most of the times connected to their practice as specialists in nonconventional therapies- who approach hospitals offering their knowledge and specific practice and see themselves as peers of the rest of professionals working at the institution. 
In these cases, the figure of volunteers is characterized by a higher degree of activity and participation in the promotion of new spaces. From their perspective, they define themselves as professionals in other types of medicine who -even if they haven't yet been recognized by the law that regulates medical practice (the aforementioned National Law No. 17,132)- have knowledge that enables them to undertake activities connected to the diagnose and treatment of disease. In that direction, the trait that defines them is that of seeing themselves as specialists rather than as assistants in the already established ways of volunteerism. The fact that they are not paid as a reward for their work is understood as an unwanted but necessary condition related to what they describe as a recent gap opened in hospitals towards more holistic ways of understanding the process of health-disease.

\section{Conclusions}

In this paper we indicated that the Social State or the Welfare State was defined by responding to the demands of the civil society with the design and implementation of social practices of a universalistic nature. This became -at least in formal terms- a perspective prioritizing the integration and inclusion of the general population above the distinctive traits of the individuals that form it. The crisis of this model and the following emergence of what has been called the 'Post-social State' have brought about transformations in the ways in which interventions on reality are taken into action, both from the sphere of state policies and practices driven by society.

When referring specifically to the health sphere, it is possible to observe that the passage from one State model to the other translates -among other things- into the deepening of the gap separating the problems presented by society, on one hand, and the capabilities of the public health institutions to confront and solve them, on the other hand. Nonetheless, this growing gap cannot be explained linearly as a simple withdrawal of the State; it is rather a consequence of a movement in which multiple factors are at stake. For instance, we could think that the economic and social context that accompanied the process of crisis of the Welfare State was itself redundant in a series of cultural changes that determined the emergence of new logics of action for the civil society. In fact, from the organization of innovative activities that emerged grouped under the figure of volunteers, different sectors had the initiative to go beyond the actions implemented by the State, even generating new values and practices in healthcare. That can be reflected in changes in the demands and needs of the population, which -we could argue- will continue to exist even in the case in which Welfare State policies continued to be sustained in the same terms as in the post-war period. As part of these transformations in what we can call the 'cultural styles' [15] of people, there is a change in the very notion of 'health', which -based on different social discourses- came to be thought of in terms of biopsycho-social well-being rather than being thought as the absence of disease. In this way, the universalizing and homogenizing logics, which were effective in the previous model, can no longer cover the broad spectrum of what we think today as 'being healthy'.

Well then, what we have just said is closely linked to what we could observe in our fieldwork. In fact, the recent inclusion of activities connected to non conventional types of medicine in the sphere of public hospitals reveals the existence of: 1) a new type of offer driven by different sectors of the civil society becoming agents via the figure of volunteers, and 2) a new type of needs found in the usual users of the public health system for whom health started being a sum of conditions strongly related to life quality and well-being. In this direction, the emergence of a new offer of workshops in the sphere of public health in the city of Buenos Aires shows the appearance of innovative institutional actions connected to specific ways to search for health, understood in a way that differs from the healing model of biomedicine.

It is worth underlining, however, that the inclusion of these activities we have called 'alternative' does not take place without tensions. In that direction, different variables that need to be taken into account are at stake, such as the legal framework that establishes the boundaries of the possibilities of volunteer actions, the regulation of tasks concerning professionals in relation to their work in the institution and, finally, the adherence of the State to a given medical logic. Therefore, even if the contents and activities of the workshops are on the hands of volunteers who-perceiving themselves as professionals in other types of medicine- design and coordinate therapeutic activities according to care paradigms different to that of biomedicine, they are not the ultimate responsible ones for these activities. On the contrary, they must respond to a general coordinator who belongs to the institutions' permanent group of biomedical professionals. Indeed, legislation is the clear boundary limiting the 
possibilities of intervention on bodies only to biomedical professionals, regulating through diverse laws and professional rules the reach and limits of each profession in 'the art of healing'.

The differences between new and old volunteers seem to be mainly based on certain axes shaping the profile of the people acting as volunteers, such as: the features they assume when performing their roles within the hospital sphere, the reason for their entrance in the institution, time devoted to the activity and reasons that originated their actions.

As we have seen in the corpus of our study, the group of traditional volunteers is formed mainly by women over 50 without a permanent job, not registered in the labor market and with an education level varying between incomplete high school education and incomplete university education. They define themselves as company for the patients and, in all cases, as aids for health professionals, especially biomedical professionals but also social workers, psychologists and nurses. They adapt their tasks by indications given by such specialists and act under their guidance. In that direction, the responsibilities of this type of volunteers are limited to the fulfillment of the tasks given. In their activity there is no room for freedom of action or capability of questioning the task given. The motivations that drive them to act as volunteers are connected -from their perspective- to the possibility of collaborating in the healthcare process, in the care of inpatients and in the tasks supporting the work of doctors, tasks that take them about 15 weekly hours. Their trajectories within institutions are often stable through time.

On the contrary, new volunteers form a group showing a more heterogeneous mix. In this group we find both women and men between the ages of 20 and 60 with college or tertiary education and certified studies in the disciplines they teach. They are all active in the labor market, in most cases in activities connected to their specialization in an alternative therapy. They integrate to the hospital structure from a role showing new and diverse features. They see themselves as trained specialists that can have an active, independent and creative role and, even if they accept the coordination of a biomedical specialist, they also point out the existence of an external training previous to the start of their volunteer activities and divergent from the biomedical paradigm. Regarding their relation with health professionals, it is interesting to underline that they mainly interact with psychologists and psychiatrists, less with biomedical doctors and rarely with social workers or nurses. Their entrance to the hospital sphere is connected to a specific proposal, as a positive response to a call made by a member of the permanent staff of professionals who calls them for their special training. In this way, their permanence in the institution is directly related to the existence of the workshop. Their dedication as volunteers, expressed in hours of work donated, is about two or three weekly hours during a four-month period or two in a year. Motivations posed as cause and foundation for their volunteer work were connected to the possibility of offering a different perspective in terms of health and well being to the traditional biomedical view, adding new and different ways to understand health and disease. On the other hand, it shows an action targeted at the legitimation of their practices and knowledge, since these are included by Hospitals -as official public institutions, providers of care according to the biomedical paradigm.

Furthermore, we could state that marginality becomes the key concept that can allow us to understand the role of new volunteers, for many reasons. On one hand, their knowledge and therapeutic practices are on the edges of the dominant biomedical paradigm. Likewise, their appointment as volunteers' places them in a peripheral condition regarding the authority held by medical professionals, but also regarding traditional volunteers, who act merely as assistants. Finally, their place within the institution is also liminal, since they remain in the institution as long as the direction accepts their proposals, an unstable situation that is repeatedly found in their accounts.

Summarizing, the reaches and limits of volunteer actions seem to point out the appearance of a type of actions that, coming from the civil society, allow showing new trends emerging around issues such as life quality and well being of the population. Nonetheless, far from being a definitive situation, it is more of a sketch of ways of action and resolve that have the peculiarity to be anchored in the institutional structures typical of a State model undergoing a reconversion process, struggling for the construction of new spaces.

\section{ACKNOWLEDGMENTS}

The authors would like to acknowledge the funding extended by the National Council for Scientific and Technical Promotion of Argentina. Also we would like to appreciate the precious time and openhanded collaboration given by coordinators and volunteers. 


\section{REFERENCES}

[1] Fengyan, T. \& N. Morrow-Howell, S. Hong. Inclusion of Diverse Older Populations in Volunteering: The Importance of Institutional Facilitation. Nonprofit and Voluntary Sector Quarterly, 38 (5), 810-827. (2009).

[2] Erlinghagen, M. \& Hank, K. Participación de las personas mayores europeas en el trabajo de voluntariado. Perfiles y tendencias. Boletín sobre el envejecimiento, 17, 1-24. Participation of European seniors in volunteer work. Profiles and trends. Bulletin on Ageing, 17, 1-24. (2005).

[3] Komp, K. \& T. Van Tilburg, M. Broese Van Groenou. Age, Retirement, and Health as Factors in Volunteering in Later Life. Nonprofit and Voluntary Sector Quarterly, 41 (2), 280-299. (2012).

[4] Montero García, I. \& M. Bedmar Moreno. Ocio, tiempo libre y voluntariado en personas mayores. Polis, 9 (26), 3-19. Leisure, free time and volunteer seniors. Polis, 9( 26), 3-19. (2010).

[5] Fleury, M. \& G. Grenier, J. Bamvita, H. Wallot, M. Perreault. Determinants of Referral to the Public Health care and Social Sector by Nonprofit Organizations. Clinical Profile and Interorganizational Characteristics. Nonprofit and Voluntary Sector Quarterly, 41 (2), 257-279. (2012).

[6] Serna, M. G. La diversidad y el contexto cambiante del voluntariado en México. Espiral, 16 (47), 141-172. The diversity and the changing context of volunteering in Mexico. Espiral, 16 (47), 141-172. (2010).

[7] Author, Author \& Author (2011)

[8] Dixit, S. Meaning and Explanations of Mental Illness: A Social Representations Approach Psychology \& Developing Societies, 17 (1): 1-18. (2005)

[9] Thorne, S. Data analysis in qualitative research. Evidence Based Nursing, 3, 68-70. (2000).

[10] Author \& Author (2012)

[11] Author et al (2011)

[12] World Health Organization. WHO Traditional Medicine Strategy 2002-2005. Ginebra: OMS. (2002).

[13] Naja, F. \& M. Alameddine, L. Hitani, H, Shoaib, D. Hariri and S. Talhouk. The use of Complementary and Alternative Medicine among Lebanese Adults: Results from a National Survey. Evidence Based Complementary and Alternative Medicine, Vol. 2015. (2015).

[14] Clavarino, A. \& P. Yates. Fear, Faith or Racional Choice: Understanding the users of Alternative Therapies. In G. Lupton \& J. Najman (Eds), Sociology of Health and Illness: Australian Readings ( 252-75). Melbourne, Australia: Macmillan. (1995).

[15] Douglas, M. Estilos de Pensar. Ensayo Crítico sobre el buen gusto. Barcelona: Gedisa. Thought Styles. Critical essay on taste. Barcelona: Gedisa. (1998). 


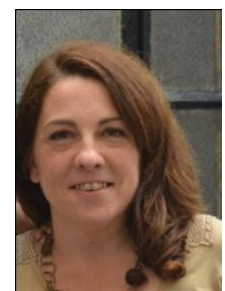

\section{Maria Mercedes Saizar}

$\mathrm{PhD}$ in Culture and Society, National University of Arts-UNA (2006)

Researcher at Argentine Center of American-Ethnology- National Council of Scientific and Technological Research-(CONICET in spanish)

Associate Professor in Folklore -UNA-.

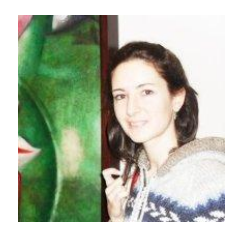

\section{Mariana Bordes}

$\mathrm{PhD}$ in Social Sciences (University of Buenos Aires)

Researcher from the National Scientific and Technical Research Council (CONICET)

Lecturer in Epistemology of Social Sciences, University of El Salvador.

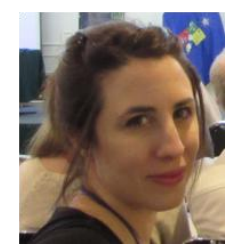

Mercedes Sarudiansky, PhD.

Assistant Researcher - National Scientific and Technical Research Council of Argentina (CONICET)

Assistant Professor - Department of Psychology - University of Buenos Aires

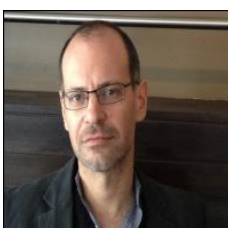

\section{PhD. Guido Pablo Korman}

Researcher from the National Scientific and Technical Research Council (CONICET)

Professor of the University of Buenos Aires

Member of the Academy of Cognitive Therapy as Research Scientist

Member of the Society for Psychotherapy Research 